\title{
Study of Changing Features of Precipitation from 1900-2010 Years in Africa-Asia Arid and Semi-Arid Area
}

\author{
Xiangkun Cheng' ${ }^{1}$ Hang Cheng2 ${ }^{*}$, Guowu Sun ${ }^{3}$, Xiaomeng Shi ${ }^{4}$ \\ ${ }^{1}$ Jinzhou District Meteorological Bureau of Dalian, Dalian, China \\ ${ }^{2}$ Dalian Meteorological Bureau, Dalian, China \\ ${ }^{3}$ Institute of Arid Meteorology, China Meteorological Administration, Lanzhou, China \\ ${ }^{4}$ Qingdao Meteorological Bureau, Qingdao, China \\ Email: ${ }^{*} 415391886 @ q q . c o m$
}

How to cite this paper: Cheng, X.K., Cheng, H., Sun, G.W. and Shi, X.M. (2017) Study of Changing Features of Precipitation from 1900-2010 Years in Africa-Asia Arid and Semi-Arid Area. Journal of Geoscience and Environment Protection, 5, 62-72. http://dx.doi.org/10.4236/gep.2017.51004

Received: December 5, 2016

Accepted: January 13, 2017

Published: January 16, 2017

Copyright $\odot 2017$ by authors and Scientific Research Publishing Inc. This work is licensed under the Creative Commons Attribution International License (CC BY 4.0).

http://creativecommons.org/licenses/by/4.0/

\begin{abstract}
The relationship between time-space variation characteristics and the variation of the general atmospheric circulation of rainfall occurred in Asia, Africa through North Africa-Middle East-Western Middle Asia-Eastern Middle Asia, Northwest China-Eastern Northwest China-North China and Northeast China is studied based on the analysis of GPCC rainfall data from 1901 to 2010 and annual precipitation in relevant cities of China from 1901 to 2010, and the data of NCEP of surface pressure as well as $500 \mathrm{Hpa}$ potential high from 1950 to 2010. The result shows that the total precipitation presents a decreasing trend in north Africa to the northeast of China in recent 100 years. It has a mutation in 1950s. The precipitation presented a decreasing trend in North Africa and Middle East, in recent 100 years; it presented a further decreasing trend after 1950s. It presented a decreasing trend before 1950s and an increasing trend after 1950s in Middle Asia and Northwest china. It also presented a decreasing trend before 1950s and an increasing trend between 1950s to 1990s, and decreased later in Eastern Northwest China, North China and Northeast China which also presented in a more or less period in different areas from North Africa to Northeast China. The beginning of less precipitation years and less period occurred after it presented less period in north Africa in time and space. After it moved to the east areas as the year past, at last, the SLPA fields which presented more or less precipitations of years from North Africa to Northeast China were analyzed. It also shows that the SLPA fields which presented more were beneficial to the precipitations and presented negative effects of precipitations in the polar, high and mid- and lower latitudes.
\end{abstract}

\section{Keywords}

Asia-Africa, Arid and Semi-Arid Region, Rainfall above or below the Normal 
Precipitation, Sea Lever Pressure Anomalies

\section{Introduction}

Drought is a global issue. Drought can happen at any country, any region, any time and any season [1]. Normally, the yearly rainfall less than $250 \mathrm{~mm}$ is defined as arid areas. The arid areas cover $25 \%$ of the land surface of the earth. The majority arid areas are located at Central Africa, Northern Africa, Middle East, Central Asia and northern part of China.

Among the meteorological disasters, such as torrential rain, strong wind, lowtemperature, hale and sandstorm, most of them are local, short timed, and discontinuous. But the drought is in much larger areas, longer term and continuous. It can cause huge damage to industry and agriculture due to the water shortage.

In 20th century, there were several severe droughts which caused very serious damage. For instance, in 1928-1929, a drought happened in Northwest China affected 9.4 million people in Shanxi Province only and caused 2.4 million casualties. In 1930s, a severe drought happened in last several years in the US and caused serious effects to the people in the area. In 1968-1973, the drought in Africa impacted 25 million people. The total death was over 2 million. In 20092011, the drought in Southwest China caused a serious impact on the people in the area [2] [3].

In recent years, especially the years after the new century, because of the global warming, the number of droughts happened more and more frequently; the time lasted longer; the intensity became stronger; the disaster areas became more widely and the damage became more severely.

Because of this, many meteorologists and researchers study the drought from different angles such as drought monitoring (rainfall, soil moisture and drought index), drought prediction (statistics and numeric modelling), mechanism (general atmospheric circulation evolutions. dynamic diagnose of climatic) and countermeasure (the method of anti-drought, actions) [1] [4]-[8].

There are some researches which are trying to analyze the climate change to the arid and semi-arid regions. However, it is not enough. [9] analyzed the change of rainfall and temperature to 9 arid regions. But it only described the basic information for each region. [10] and others analyzed the rainfall change in different arid regions in Asia and Africa as well as the relation between the rainfall and the drought as well as the possibility of the drought transferring from West to East in these areas. Based on Sun's work, Ma and others [11] discussed the possible earth quake triggering mechanism of the drought transferring. However, it is about 20 years ago.

This article analyzes different arid areas, semiarid areas and its interrelationships of time-space evolution characteristics from North Africa-Middle EastMiddle Asia-Northwest China-North China and Northeast China in recent 100 years (1900-2010). The research of possible reasons and relationships between arid areas was based on the analysis of anomaly of circulation. 


\section{Data}

\subsection{Used Data}

Precipitation of recent 100 years (GPCC). The data of (NCEP) sea level pressure and precipitation of Huhehaote, Xi'an, Lanzhou in China for recent 60 years.

\subsection{Division}

Divide Africa and arid Africa into 7 regions. This 7 regions show NE-SW trend from A-G, Includ arid areas whose precipitation is lower than $250 \mathrm{~mm}$. There are North Africa, Middle East, Middle Asia and Western China and semiarid area whose precipitations are $300-500 \mathrm{~mm}$ such as eastern Northwest China, North China and Northeast China areas (Figure 1, Table 1).

\subsection{Comparison}

By the judgment of the credibility of GPCC precipitation, areas with a large precipitation rate have been chosen, such as different stations Huhehaohe $\left(40.48^{\circ} \mathrm{N}\right.$, $\left.111.41^{\circ} \mathrm{E}\right)$, Lanzhou $\left(36^{\circ} \mathrm{N}, 103.40^{\circ} \mathrm{E}\right)$ and Xian $\left.34.17^{\circ} \mathrm{N}, 108.57^{\circ} \mathrm{E}\right)$ in Northwest China and North China, they have the same annual precipitation in GPCC and the curves were made as following (Figure 2).

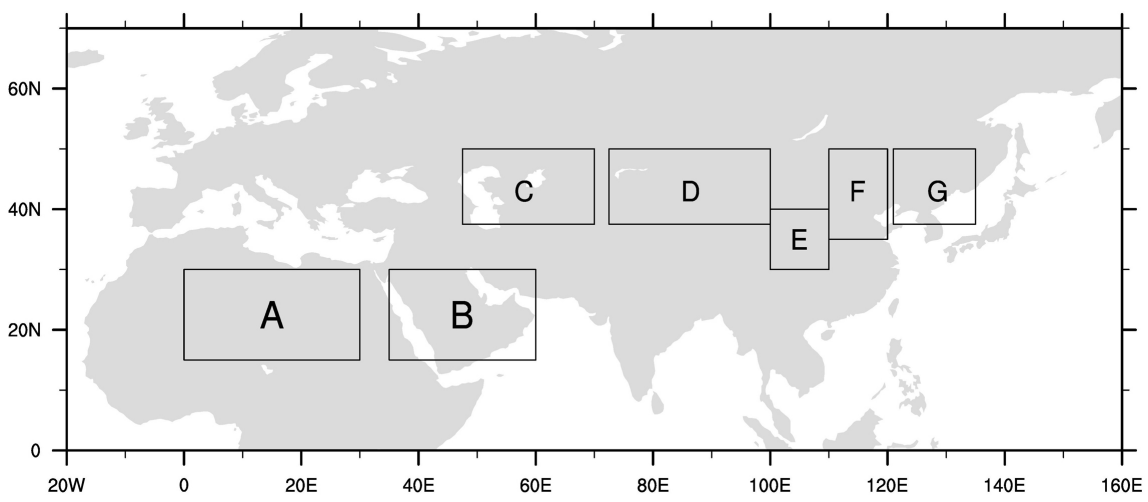

Figure 1. Geographical position of the 7 subregions, A: North Africa, B: Middle East, C: Western Middle Asia, D: Eastern Middle Asia and Northwest China, E: Eastern Northwest China, F: North China and G: Northeast China.

Table 1. Regional range of 7 areas of Asia and Afica.

\begin{tabular}{lc}
\hline Region & Range \\
\hline A (North Africa) & $0^{\circ}-30^{\circ} \mathrm{E}, 15^{\circ}-30^{\circ} \mathrm{N}$ \\
B (Middle East) & $35^{\circ}-60^{\circ} \mathrm{E}, 15^{\circ}-30^{\circ} \mathrm{N}$ \\
C (Western Middle Asia) & $47.5^{\circ}-70^{\circ} \mathrm{E}, 37.5^{\circ}-50^{\circ} \mathrm{N}$ \\
D (Eastern Middle Asia and Northwest China) & $72.5^{\circ}-100^{\circ} \mathrm{E}, 37.5^{\circ}-50^{\circ} \mathrm{N}$ \\
E (Eastern Northwest China) & $100^{\circ}-110^{\circ} \mathrm{E}, 30^{\circ}-40^{\circ} \mathrm{N}$ \\
F (North China) & $110^{\circ}-120^{\circ} \mathrm{E}, 35^{\circ}-50^{\circ} \mathrm{N}$ \\
G (Northeast China) & $121^{\circ}-135^{\circ} \mathrm{E}, 37.5^{\circ}-50^{\circ} \mathrm{N}$ \\
\hline
\end{tabular}



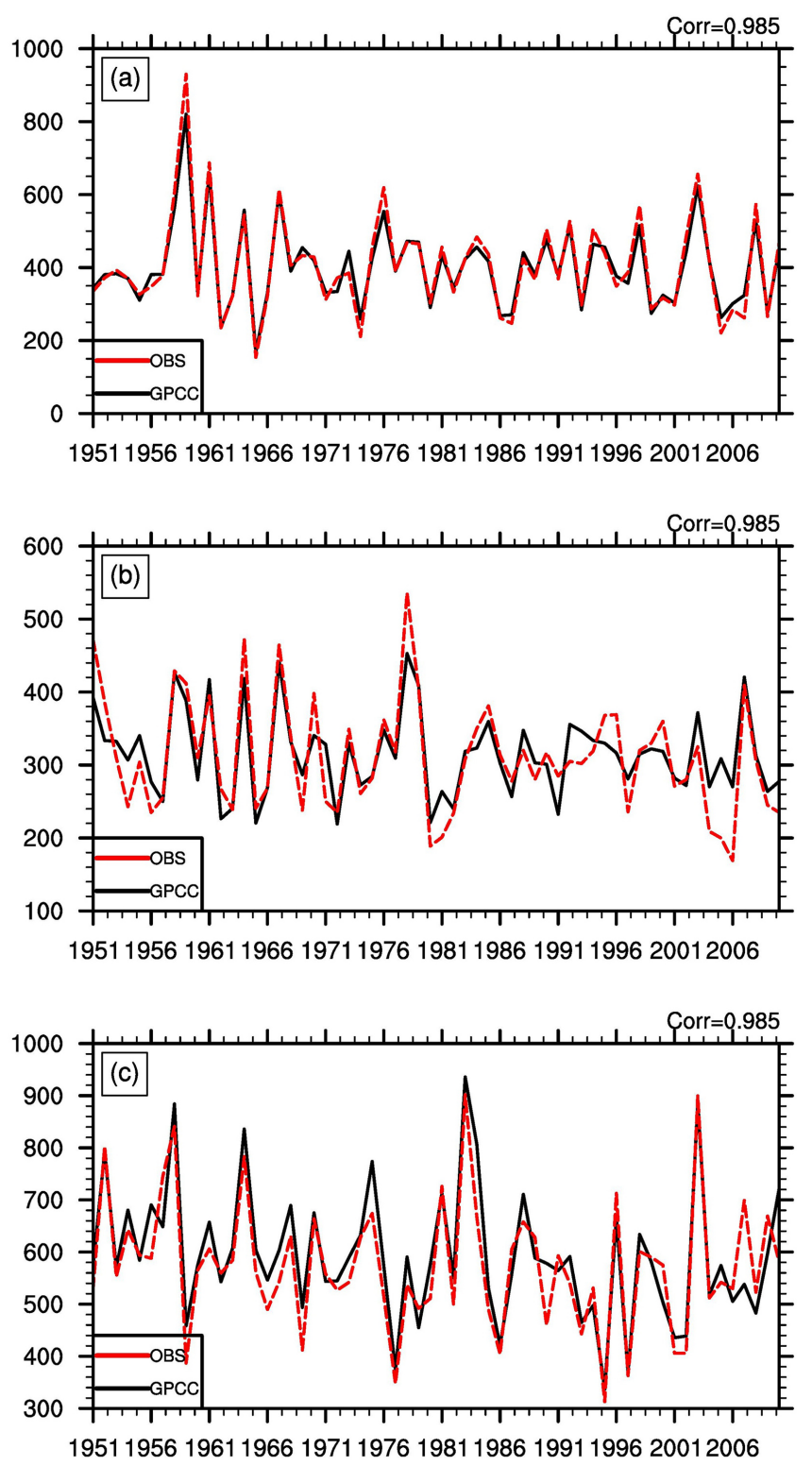

Figure 2. Shows both of them not only have the same changing trend but also the same absolute values. It shows that the GPCC data is appropriate.

\section{Arid Climate}

\subsection{Temporal Evolution Characteristics}

Figure 3 is the curve of the precipitation from region A to G. From Figure 3, we can conclude that in recent 100 years, annual variations and chronological changes of most regions are synchronizated. But there still exist some which are not synchronizated, which are well coincident in region A and B. Both of them represent a decreasing trend (Figure 3(a), Figure 3(b)). Region C is closed to D. It presented a decreasing trend before 1951 and a rising trend after 1951. (Figure 3(c), Figure 3(d)), but E and F are different from D. They showed a decreasing trend before 1951, from 1951 to 1995 they showed a rising trend, and a decreasing trend again from 1995 to 2010 (Figures 3(e)-(g)). 

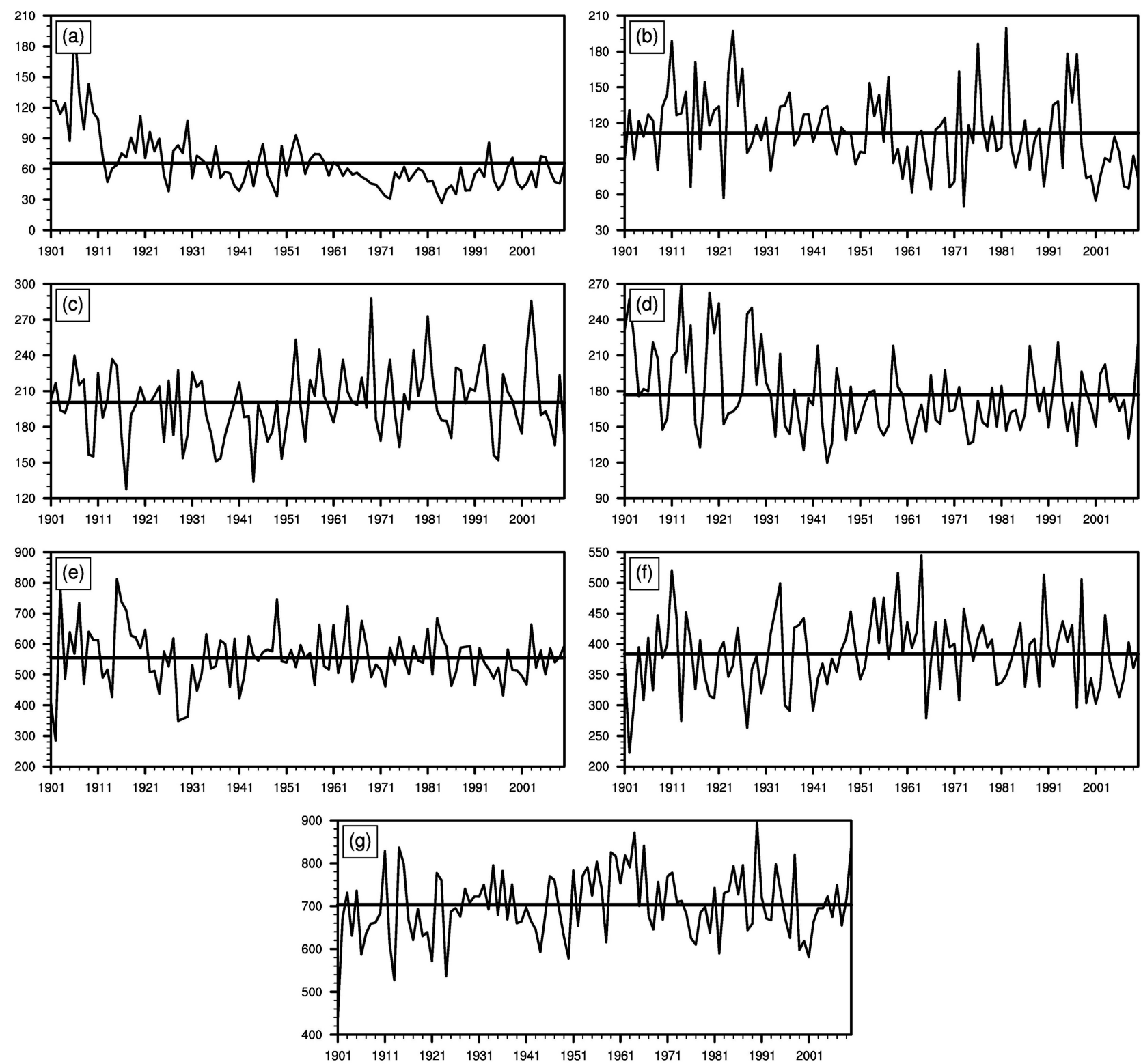

Figure 3. The curve of precipitation of each area from 1900 to 2010 unit (mm). (a), (b), (c), (d), (e), (f) and (g) represent regions of $\mathrm{A}, \mathrm{B}, \mathrm{C}, \mathrm{D}, \mathrm{E}, \mathrm{F}$.

Above all, the annual precipitation presented a decreasing trend in North Africa and Middle East (region A B) in recent 100 years. The precipitation presented a decreasing trend before 1951 in Middle Asia and East of Northwest China (region C, D), and in the east of Northwest China North of North China and Northeast China (region E F G). It showed a rising trend after 1951 as it showed a decreasing trend before 1951. From 1951 to 1995 the precipitation presented a rising trend whereas from 1995 to 2010 the annual precipitation showed a decreasing trend.

From the wavelet analysis data we can conclude that. Periods of 4 - 6 years, 8 12 years and 10 - 25 years (or 15 - 30) exist in each region. And the periods of changing are stable which do not vary with years. According to the analysis of 
M-K mutation method, the catastrophe point appeared in region A to G in 1950. It presented a decreasing trend of precipitation after 1950s in region A and $\mathrm{B}$. Besides, in region C, D, E, F and G, the precipitation turned to a rising trend after 1950. But in the middle of 1990s, a mutation happened in semiarid area in which more precipitation turned to be less.

According to Figure 3, the variation curve of precipitation from 1901 to 2010 in each region prescribe the periods in which the annual precipitation anomaly was minus for lasting 3 years are defined as a less precipitation year, and we get the less precipitation years in each region as listed in Table 2. According to Table 2, the begin and the end date of the less precipitation years are not identical in each region. But there are still a few decades of less precipitation year in each region at the same time such as in 1930-1940s, less precipitation years occurred in each region. The meaningful thing is that by putting the initial years of the less years together. (Table 3 ) we find that as the years go on it shows a symptom of eastwards shifting and the plastochronis 20 years or so from North Africa to Northeast China. For example in Figure 3 the less years started in 1936 in region A. But after 20 years, the less years started in 195719812002 in regions b, c and

Table 2. The less precipitation years of each region.

\begin{tabular}{|c|c|c|c|c|c|}
\hline \multirow{2}{*}{$\begin{array}{c}\text { Regions } \\
\mathrm{A}\end{array}$} & \multicolumn{5}{|c|}{ Less precipitation years } \\
\hline & & & & 1936-1948 & $1959-2010$ \\
\hline B & & & 1944-1951 & $1957-1991$ & $1997-2010$ \\
\hline $\mathrm{C}$ & & & $1935-1954$ & 1981-1985 & $2003-2007$ \\
\hline $\mathrm{D}$ & & & $1933-1956$ & 1973-1983 & $2002-2008$ \\
\hline $\mathrm{E}$ & 1901-1902 & $1911-1913$ & $1921-1941$ & 1969-1981 & 1991-2002 \\
\hline $\mathrm{F}$ & 1901-1906 & $1918-1931$ & 1941-1945 & 1981-1985 & $1998-2000$ \\
\hline G & 1901-1909 & $1917-1926$ & $1936-1942$ & 1965-1982 & $1991-2008$ \\
\hline
\end{tabular}

Table 3. The initial of less precipitation years of each region from 1901-2010 in each region.

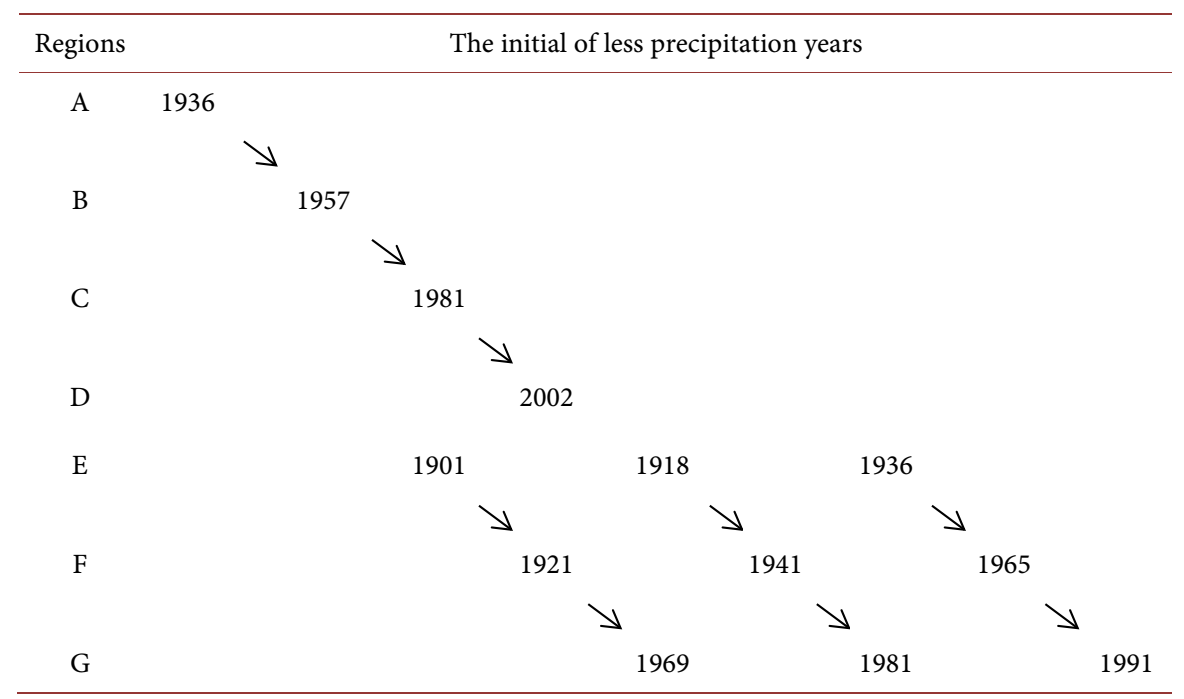


d. This phenomenon coincides with the results in the literature, only eastwards shifting plastochrons are different.

\subsection{Spatial Evolution Characters}

Figure 4 shows the average annual precipitation anomaly field from 1901 to 2010, which in the less range $5-100 \mathrm{~m}$ of the average annual precipitation anomaly field from the Arid and Semi-arid Areas of North Africa-Middle EastMiddle Asia-Northwest China-North China-Northeast China But showed a SWNE trend.

Region A-G become into one piece, we can also conclude from point correlogram. Choose an random point $\left(45^{\circ} \mathrm{N}, 75^{\circ} \mathrm{E}\right)$ in region $\mathrm{A}$, a point $\left(45^{\circ} \mathrm{N}, 75^{\circ} \mathrm{E}\right)$ in region $\mathrm{D}$ and a point $\left(43^{\circ} \mathrm{N}, 123^{\circ} \mathrm{E}\right)$ in region $\mathrm{G}$, then calculate the correlation coefficient of these points with other grid $\left(2.5^{\circ} \times 2.5^{\circ}\right)$ in Asia Africa areas. We found that the correlation coefficient in Arid and Semi-arid areas of region A-G is larger than 0.7. It shows that regions in $500 \mathrm{Hpa}$ geopotential height field have a positive correlation, And also the same Arid and Semi-arid climates. The point correlogram of region $\mathrm{G}$ has been shown in Figure 5.

From Figures 4(b)-(i) we can see that the spatial distribution of A-G is basically identical with the time distribution of Figure 3. Since 1950, there are negative anomaly areas of annual precipitations became more than before as the precipitations became less in region A and B. But it presented opposite in regions C-G. The negative anomaly areas of annual precipitations were less than before in 1950s whereas the precipitations presented a rising trend. But it showed a decreasing trend of precipitations after 2000 in semi-arid Areas (regions E F and G). What is meaningful is that from Figures 4(b)-(i) we also find that the less precipitation years showed a eastward shifting trend as years go on, As shown in Figure 4, in the areas of S, it shifted in sequence from North Africa to Middle East Middle Asia Northwest China North China and finally to Northeast China areas since 1910s, which has the same results as in section B.

\section{The Relations of the Changes of Atmosphere Circulation}

The more or less precipitations of a region always correspond with the changes of local atmosphere circulation. This paper selects less precipitations years in each regions (A-G) in years 1977, 1982, 1999, 2001 and 2008. And the years of 1987, 1990, 1994, 1998 and 2010 which had more precipitations at the same time to analyzes the SLPA anomaly field of years which had more precipitations and less precipitation (Figure 6(a), Figure 6(b)). The results show that there are obvious differences between the years which had more precipitations and less precipitation in pressure situation field.

The polar and the high-latitude regions are strong pressure negative anomaly areas in more precipitation years. But in low and middle latitude areas, they are the strong pressure positive anomaly areas, especially from the North of North Africa to Northeast China is for negative anomaly areas, and in the south of the areas are negative anomaly, for the low pressure is deeper in the north of that 

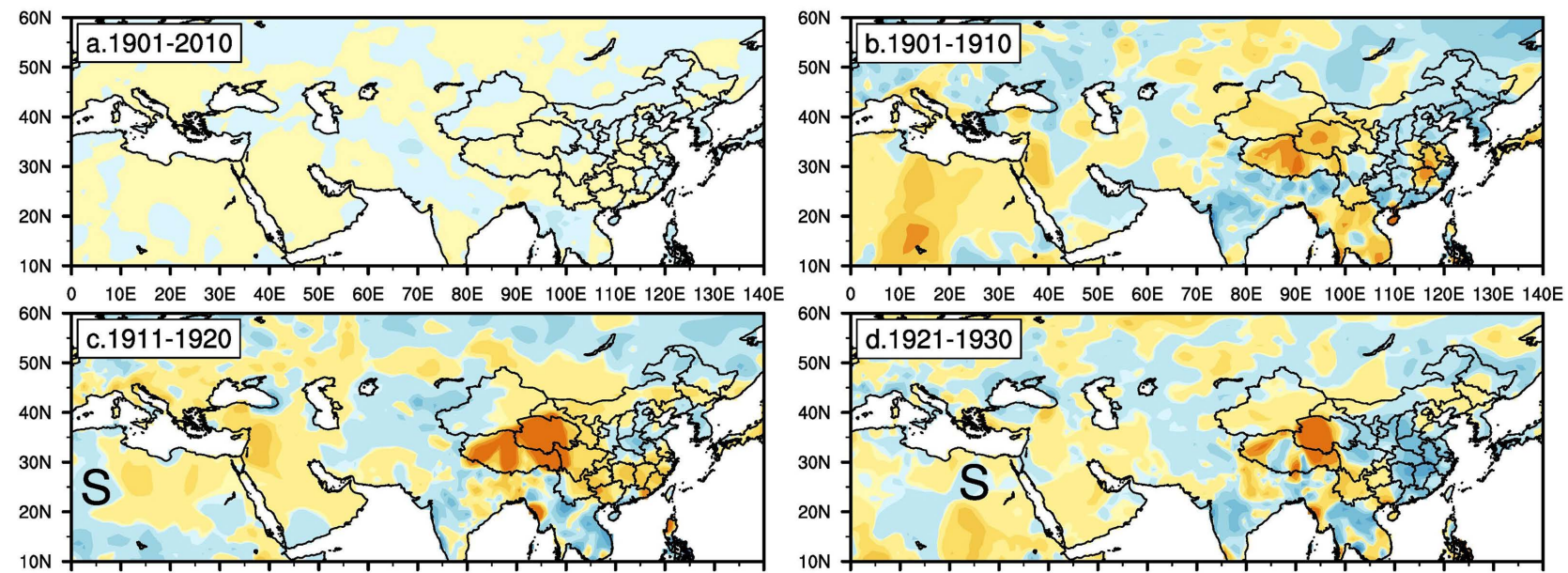

0 10E 20E 30E 40E 50E G0E 70E 80E 90E 100E $110 \mathrm{E}$ 120E $130 \mathrm{E}$ 140E
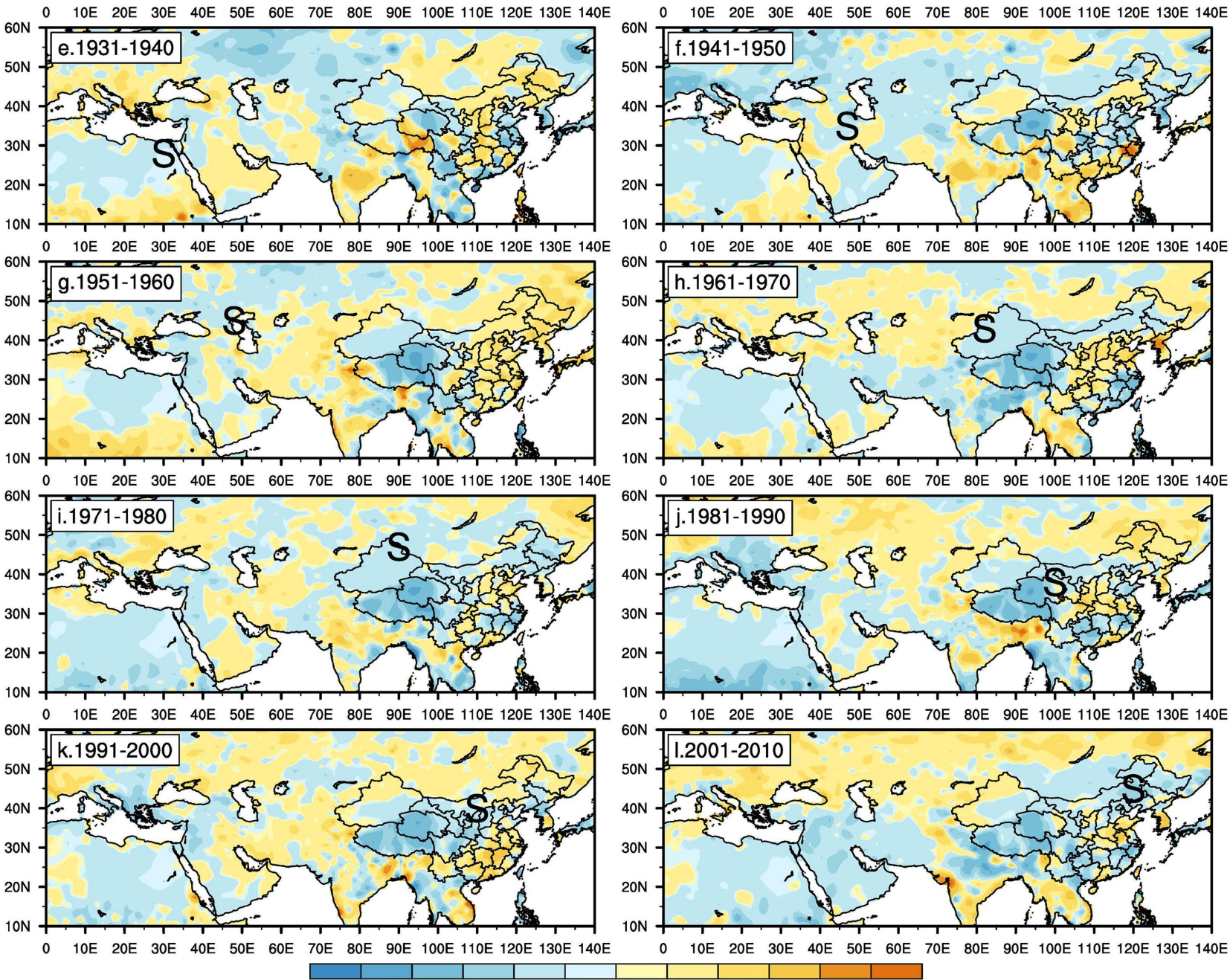
$\begin{array}{cccccccccccccc}\mid & \mid & \mid & \mid & & & & & \mid & \mid & \mid & \mid \\ -300 & -200 & -100 & -50 & -5 & 0 & 5 & 50 & 100 & 200 & 300\end{array}$

Figure 4. The annual precipitations anomaliezed in Asia and Africa(including regions of A B C D E F and G) (a), (b), (c), (d), (e), (f), (g), (h), (i), (j), (k), (l) is the average precipitation in the period 1901-2010, 1901-1910, 1911-1920, 1921-1930, 1931-1940, 1941-1950, 1951-1960, 1961-1970, 1971-1980, 1981-1990, 1991-2000, 2001-2010.

areas and is stronger in the south of that areas. Both of the strong pressure systems have stalemated in north and south areas, which is beneficial to the precipitations. On contrary to less precipitation years, the polar and the high-latitude 


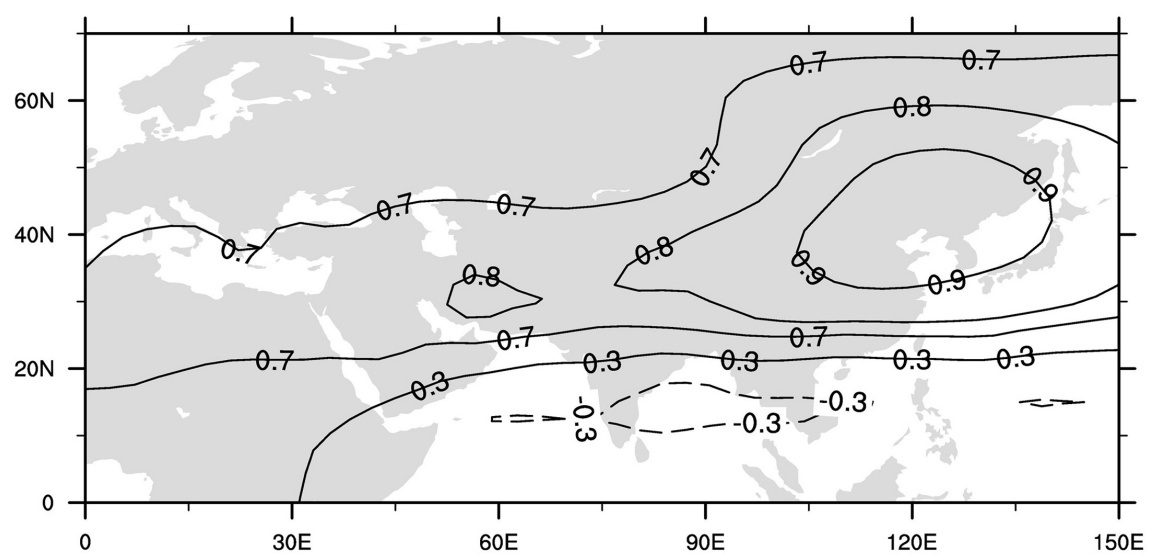

Figure 5. The less precipitation years of $500 \mathrm{Hpa}$ geopotential height field point correlogram in region $\mathrm{G}\left(43^{\circ} \mathrm{N}, 123^{\circ} \mathrm{E}\right)$.

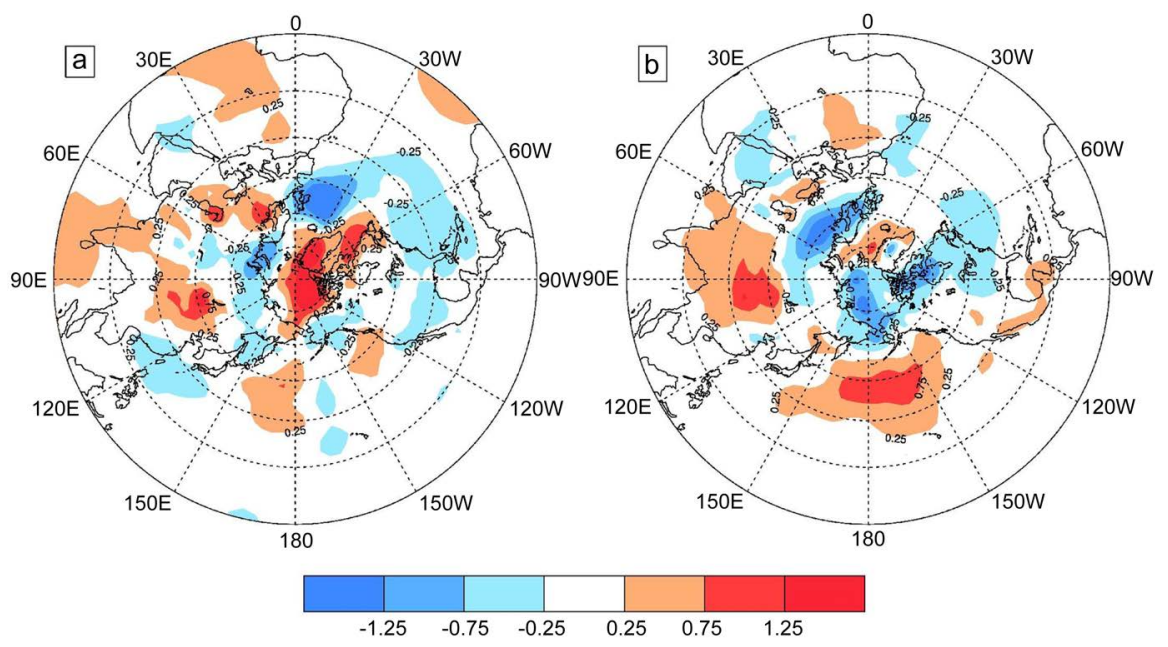

Figure 6. The composition graph of the SLPA anomaly field of the more precipitation years and less precipitation years in each region (unit: Hpa).

regions are strong pressure positive anomaly areas. And in the south of the highlatitude regions of this area (Atlantic ocean and the Asian continent) it presents negative anomaly, and to the further south of North Africa and Northeast China it presents positive anomaly. This distribution of the pressure which makes the of low pressure in the North areas stalemates the high pressure in the south areas as the northward of region A to G, it goes against the precipitations.

\section{Summary}

The results from this study can be summarized as follows:

From the annual precipitations of North Africa (region A), Middle East (region B), western Middle Asia (region C), Eastern Middle Asia and Northwest China (region D), Eastern Northwest China (region E), North of North China (region F), and Northeast China (region G) from 1901 to 2010, we can see that, all in all, in most areas from A to G, the precipitations showed a decreasing trend in centuries. On concrete conditions: 
1) During the last 100 years, the precipitations showed a decreasing trend in regions $\mathrm{A}$ and $\mathrm{B}$, and the mutations had appeared in 1950s where the precipitations presented further reduced. In regions $\mathrm{C}$ and $\mathrm{D}$ the precipitations showed a decreasing trend before 1950s. But after 1950s it showed a rising trend where the precipitations became more accompanied with the mutations in 1950s. The precipitations presented a decreasing trend before 1950s whereas from 1950s to 1990s, it showed a rising trend, and the precipitations increased. But from the end of last century to the beginning of this century, it presented a decreasing trend and the precipitations decreased. The mutations also appeared in 1950s.

2) Regions from $A$ to $G$ have the same periodic variations, such as $4-6$ years, 8 - 12 years and 10 - 25 years (or 15 - 30 years).

3) The arid and semi-arid areas in regions A-G became into one piece. For one hundred years, although they were arid and semi-arid areas, the precipitations showed an obvious period which had more precipitations, especially in the less period. Analysis at less initial years indicates that from either the temporal evolution or the spatial evolution, both the less initial years and the less regions had a shifting trend from North Africa Middle East Northwest China North China to Northeast China.

4) From composition graph of SLPA anomaly field of the more typical annual precipitations years and less typical annual precipitations years in each region (regions A-G) we can see that, the years with more or less precipitations had obvious differences. On the one hand the polar and the high-latitude areas showed a strong pressure negative anomaly, and to the southward it is strongly positive anomaly areas. It shows that the strong areas to the northward of low pressure and to the southward of high pressure in regions A-G stalemated in these regions which were beneficial to the precipitations. As it was opposite to the less precipitation years, the polar and the high-latitude areas showed strong pressure negative anomaly. As the south of the Atlantic Ocean and the Asian continent presented negative anomaly, the further south of it showed positive anomaly. This made the stalemated areas of the north low pressure and the south high pressure zones northward, as in the north of regions A-G, which goes against precipitations.

\section{Acknowledgements}

Thanks Assistant Engineer Zang Di for the information collection and drawing.

\section{References}

[1] Cook, B.I., Miller, R.L. and Seager, R. (2009) Amplification of the North American "Dust Bowl" Drought through Human-Induced Land Degradation. Proceedings of the National Academy of Sciences of the United States of America, 106, 4997-5001. https://doi.org/10.1073/pnas.0810200106

[2] Liu, T., Yan, T.C., et al. (2011) Main Meteorological Disasters in China and Their Economic Losses. Journal of Natural Disasters, 20, 90-95. (In Chinese)

[3] Sun, G.W., Li, Z. and Feng, J.Y. (2014) Relationship between Atmospheric Low Frequency Oscillation and Two Severe Drought Event in Southwest China. Plateau 
Meteorology, 33, 1562-1567.

[4] Sun, G.W., Luo, Z.X. and Li, Z.Y. (1997) Study of Arid Climate in Northwest China. Arid Climate Atlas of China, 1-113.

[5] Ding, Y.H. and Shi, G.Y. (1997) Study of Climate Change and Climate Influence of China. Arid Climate Atlas of China, 195-364.

[6] Huang, R.H., Li, R.Y., Wang, S.W., et al. (2003) Severe Climatic Disasters in China and Their Formation Mechanism. Beijing Meteorological Press, 343-443.

[7] Qing, D.H., Chen, X.Y., Li, Y.Y., et al. (2005) Advances in Climate Change Research. Beijing Meteorological Press, 1-41.

[8] Dai, A. (2011) Characteristics and Trends in Various Forms of the Palmer Drought Severity Index (PDSI) during 1900-2008. Journal of Geophysical Research, 116, D12115. https://doi.org/10.1029/2010JD015541

[9] Hulme, M. (1996) Recent Climate Change in the World's Dryland. Geophysical Research Letters, 23, 61-64. https://doi.org/10.1029/95GL03586

[10] Sun, G.W. and Ye, Q. (1996) A Study on the Variation of Drought Periods Occurring in Northwest China and Other Africa-Asia Continental Regions. ACTA Meteorol Sini, 10, 473-484.

[11] Ma, Z.J. and Du, P.H. (1995) Orientational Migration of Earthquakes and Drought and Formation Mechanism. Quaternay Sciences, 5, 397-403.

\section{Submit or recommend next manuscript to SCIRP and we will provide best} service for you:

Accepting pre-submission inquiries through Email, Facebook, LinkedIn, Twitter, etc. A wide selection of journals (inclusive of 9 subjects, more than 200 journals)

Providing 24-hour high-quality service

User-friendly online submission system

Fair and swift peer-review system

Efficient typesetting and proofreading procedure

Display of the result of downloads and visits, as well as the number of cited articles

Maximum dissemination of your research work

Submit your manuscript at: http://papersubmission.scirp.org/

Or contact gep@scirp.org 